\title{
An Active Power Filter Method to Improve the Line Current Spectrum of PWM Locomotive Rectifiers with Load Unbalance
}

\author{
Vijay Kuppa, Peter Wolfs, Steven Senini \\ Centre for Railway Engineering \\ Faculty of Engineering and Physical Systems \\ Central Queensland University \\ Rockhampton. Qld.4702, Australia \\ v.kuppa@cqu.edu.au
}

\begin{abstract}
Locomotives in heavy haul and high speed passenger operations represent several megawatts of electrical load. Single phase power collected by a pantograph is typically rectified by multiple PWM converters. The converter switching instants are phased to ensure ripple current cancellation, assuming that the converter loads are balanced. Partial failures may result in unbalanced operation with reduced cancellation. The resulting harmonics may adversely impact the signalling systems and/or result in over voltage effects due to resonance in the overhead supply system. This paper examines a 4 MW locomotive with three rectifier modules and a device switching frequency of $900 \mathrm{~Hz}$. This results in a $5400 \mathrm{~Hz}$ ripple frequency in the mains current. Ideal balanced operation of converters is compared to an unbalanced operation case. Unbalanced cases include rectifier failures, inverter failures and changes in the relative balance of power delivered to each axle of the locomotive. This paper will consider what may be the most frequently occurring case; that of loss of load in one traction motor due to wheel slip. Current ripple cancellation is partially lost in this case and lower frequency current components can be produced. An active filter is proposed as a means to retain an acceptable harmonic performance for the locomotive.
\end{abstract}

\section{INTRODUCTION}

Pulse Width Modulated Rectifiers offer multiple advantages over other rectifier solutions in AC traction applications. They provide regenerative power capability, better power factor and reactive power control and reduced harmonics in the input current. PWM traction converters operate in multiple units at megawatt power levels to achieve high power and high switching frequency operation. The rectifier units are supplied from a single phase traction transformer with multiple secondaries of high leakage reactance, allowing the switching instants to be phase shifted. The use of multiple converters not only provides better harmonic performance but also provides a higher level of redundancy of operation.

It is expected that the rectifier operations are power balanced under normal conditions, in order to ensure ripple cancellation and higher ripple rejection. However, in practical conditions, with several units and PWM converters in operation, such a condition is not always possible. Some degree of unbalanced operation of multiple converters might be expected. This will influence the overall performance of the traction system. Switching frequency harmonics, although are small in magnitude, can be quite dangerous due to their interference with the railway line communication and signalling systems and overvoltages in the overhead system due to resonance effects.

The adverse effects of harmonics raise serious concerns to both smooth running of train operations as well as economic suppression of harmonics. Valid management of power quality and prediction of harmonic content in the line currents become vital issues for rail power systems. There is a significant probability that the permissible harmonic limits and thresholds imposed on the signaling systems may be exceeded. Typical threshold limits [1, 2] are 100-300 mA rms for power frequency track circuits in the frequency range of typically 1-2 kHz.

Accordingly, it is quite important to investigate robust ways of improving the line current spectrum of the AC traction power systems. This may be achieved with better harmonic controls under such adverse unbalanced conditions of operation. This should also be achieved without causing any degradation of the operation of existing rail systems.

It is observed that the literature available on such unbalanced loading of power converters is extremely limited. Hence it is considered a quite pertinent issue to examine the problem of typical traction power converters at megawatt levels for this unbalanced operation, as a case study, which forms the rationale behind this investigation.

This paper explores the possibility of employing an Active Power Filter for compensation of unbalanced operation of traction power converters in the locomotives. The active power filter will imnprove the harmonic performance of the converter under unbalanced conditions, reducing the impact on the rail systems. The use of an active damper based control strategy provides additional benefits, which will also be shown in the results. 


\section{ACTIVE POWER FILTERS}

Active Filters are seen as the most viable alternative for improving the line current spectrum of the converters given the current state of the art of the technology. Converter loading unbalance can be corrected by employing Active Filters, which inject/reject controlled harmonics into/away from the supply systems in general.

An Active Filter is a current source connected in parallel with the load and is controlled to generate the required compensation currents. The mains supply needs to supply only the fundamental component of line current, thereby improving the power quality of the supply system [3].

Harmonic current compensation is achieved by injecting harmonic currents equal in magnitude but opposite in phase to the load currents, at the point of connection. These injected currents thereby cancel the original distortion currents and improve the power quality.

\section{LOCOMOTIVE PWM RECTIFIERS}

The use of PWM rectifiers for traction applications has become attractive as the technology has matured. Although they have significant advantages, the PWM rectifiers do expose the system to the possibility of interference. Locomotive PWM rectifiers typically use parallel converters supplied by multiple windings of a traction transformer with high leakage inductance. The switching of the converters is phase shifted to provide cancellation and raise the effective switching frequency. Under unbalanced conditions, the cancellation effect is reduced and switching currents may exceed the limits imposed to prevent negative effects. This paper will examine a typical case which is the most commonly occurring reason for unbalanced loading of the converters.

'Psophometric Current' is an index of the interference levels produced by the traction equipment [4] for harmonic currents. It needs to be constantly monitored by the signalling operators, to ensure fail-safe operation of railway signalling systems. The index takes into account the harmonic content of the primary side current of the traction transformer. It is defined as the rms addition of all the frequency weighted harmonic currents. For the case presented in this paper, it is the 1-2 $\mathrm{kHz}$ range of frequencies which is of interest [5]. The index gives an indication of the level of interference produced within this range by the traction converter [6].

This paper presents a case study using a full SIMULINK model of 4MW Locomotive with three independent PWM converter modules, each supplying a pair of traction inverters and other induction motor loads. The PWM device switching frequency is selected as $900 \mathrm{~Hz}$ and there are three converter bridges in the model, resulting in a ripple frequency of $5400 \mathrm{~Hz}$.

\section{BASIC CONVERTER OPERATION}

A detailed study and analysis of the converter model for a 4MW locomotive has been carried out in MATLAB and SIMULINK. Considering a typical traction load of about 4MW, for the three converters under consideration, under balanced load conditions, each converter is loaded to $1.33 \mathrm{MW}$ under full load. In this case, the locomotive designation is Bo Bo Bo; that is there are three groups of two driven axles. The rectifiers each supply two inverters with each inverter controlling one driven axle. The separate rectifier outputs allow easy isolation of a failed rectifier or an inverter. The general block diagram of the traction system is shown in Figure 1. The physical arrangement of the traction converter system under consideration, along with its three PWM power converters, is shown in Figure 2.

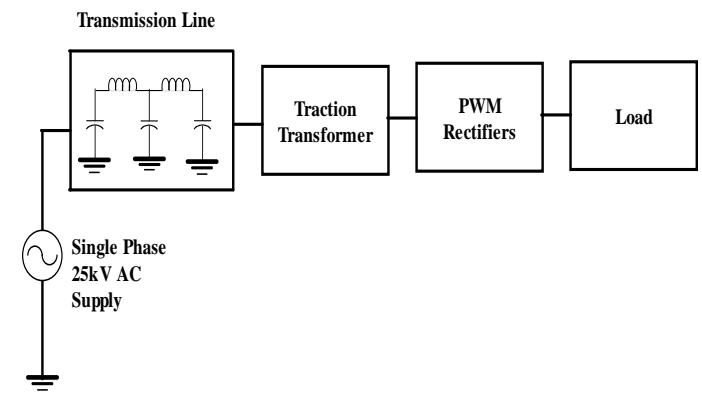

Figure 1. Block Diagram of the Traction System Model

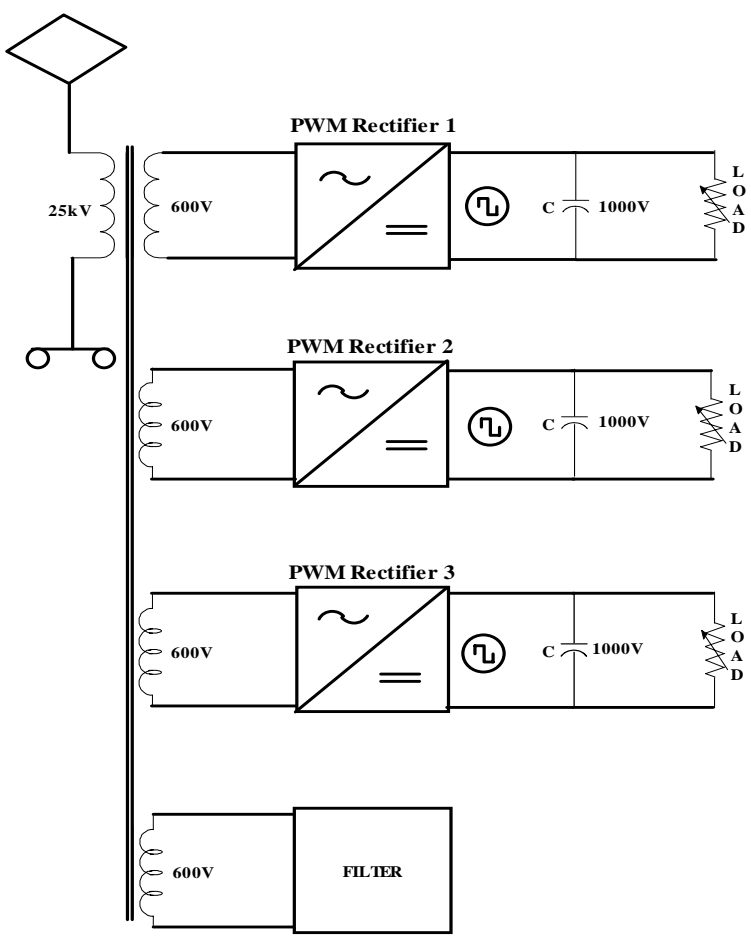

Figure 2. Physical arrangement of Traction Converter System 


\section{PWM MODULATOR/SYMMETRICAL SWITCHING CONTROLLER MODEL}

Each PWM rectifier is a full bridge converter, which operates as a boost mode rectifier as shown in Figure 3.

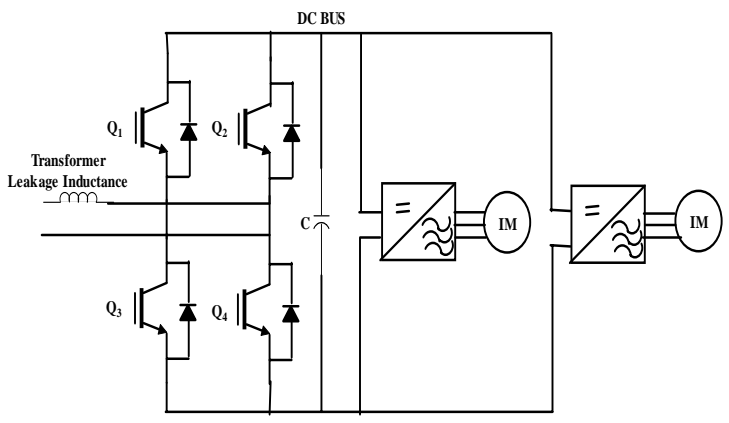

Figure 3. Rectifier and Inverter Group

Naturally sampled PWM is used with PWM switching instants being determined by the intersection of a reference waveform with a symmetrical triangular carrier waveform with a frequency of $900 \mathrm{~Hz}$. The triangular carrier waveform is phase displaced for each of the three rectifier converters to produce ripple cancellation.

Each bridge rectifier incorporates a predictive current controller scheme, where at the beginning of each switching interval a total volt-second requirement is calculated for each bridge to force the input current to track a reference with zero error.

The bridges follow a sinusoidal current demand signal that is generated by the locomotive DC bus voltage regulator, which determines the real power required to control the DC voltage. The power signal is determined using a reference model following controller [7], which produces a harmonically clean sinusoidal demand signal. This approach is superior in terms of low frequency harmonics. As the locomotive application is single phase the DC bus has significant $100 \mathrm{~Hz}$ ripple and this does cause difficulties with other control schemes [7].

Under a balanced case of converter operation the total pantograph line current waveform for the three, phase shifted converters, its line voltage waveform and the total line current spectrum along with its single converter's waveform are shown in the following figures.

Figure 4 shows the currents drawn by one of the three converters on the $600 \mathrm{~V}$ secondary winding. The switching components are quite evident in this waveform. Significant current cancellation is shown in the total pantograph current shown in Figure 5. This current is measured on the transformer primary side.

Figure 6 shows the pantograph current spectrum for the balanced case. A small current component at $5400 \mathrm{~Hz}$ should be noted.

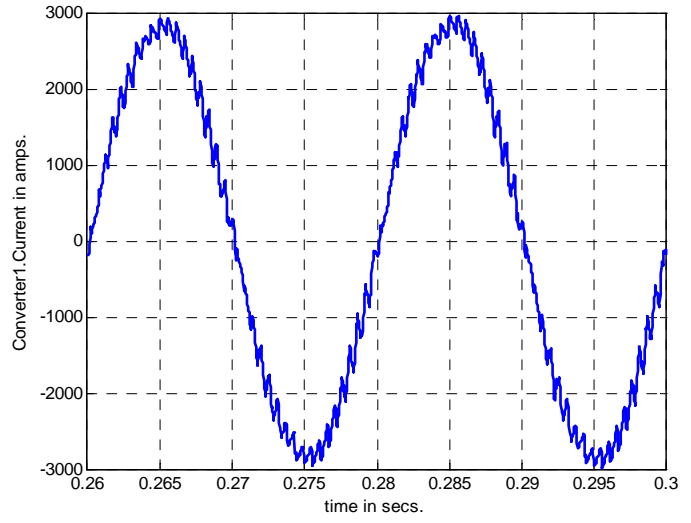

Figure 4. Single Converter Current Waveform (PWM Conveter1 Current waveform)

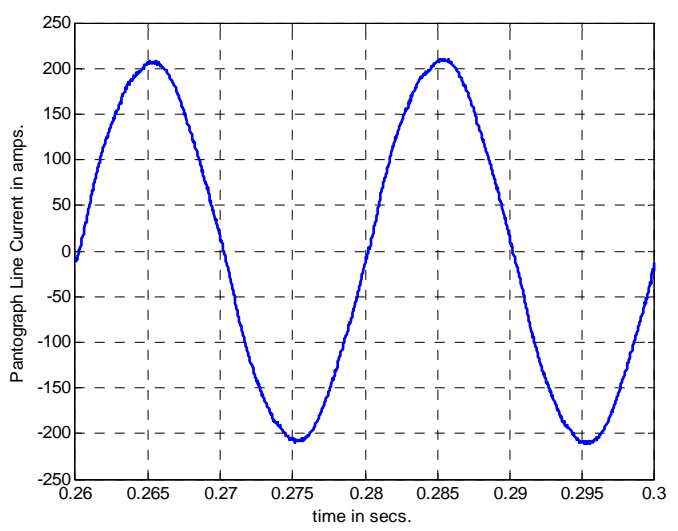

Figure 5. Pantograph Line Current waveform With phase shifted PWM Converters

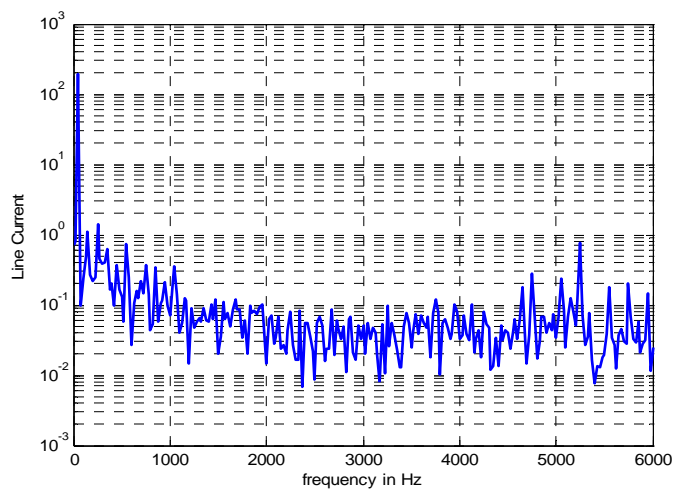

Figure 6. Pantograph Line Current Spectrum for balanced case of phase shifted PWM Converters

Figure 7 shows the pantograph voltage and some harmonic voltage amplification is visible with a dominant frequency of $5400 \mathrm{~Hz}$. In this simulation, the line length was chosen to be $3 / 4$ wavelength at $5400 \mathrm{~Hz}$ to purposely demonstrate the resonance effect. 


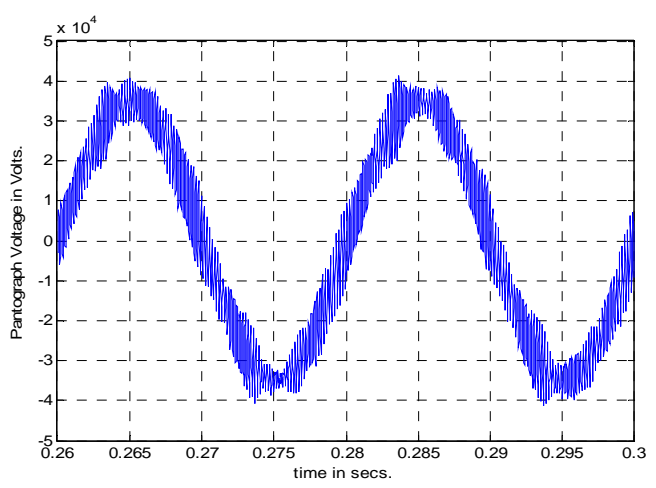

Figure 7. Pantograph Line Voltage Waveform

Figure 8 shows the line current components between $1000 \mathrm{~Hz}$ and $2000 \mathrm{~Hz}$. The currents are determined by capturing two cycles of the line current, determining the FFT, zeroing all components outside of the frequency range of interest and reconstructing the $1000-2000 \mathrm{~Hz}$ current using the inverse Fourier transform. An evaluation of RMS value of Line Current shows that $448 \mathrm{~mA}$ rms already exists even in the balanced case.

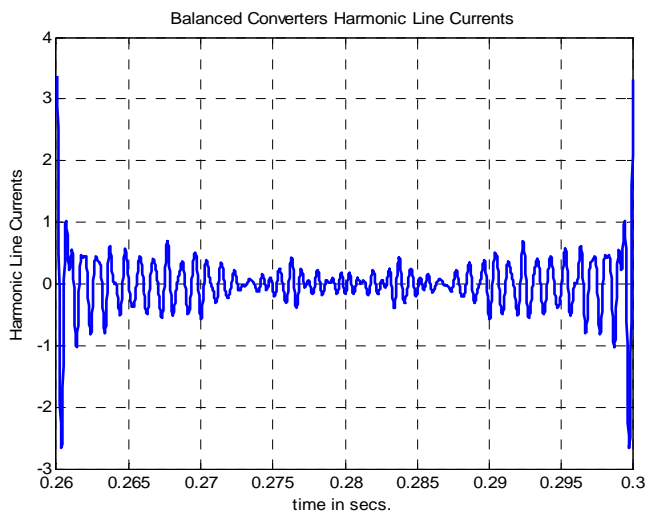

Figure 8. Harmonic Currents for the Balanced Converters for the frequency range of $1 \mathrm{kHz}-2 \mathrm{kHz}$

These currents are surely small in magnitude compared to traction currents, approximately $160 \mathrm{~A}$, but already large enough to be of sufficient concern for railway signalling. This situation deteriorates substantially with converter loading unbalance, which is discussed below.

If there is loss of load in one traction motor due to wheel slip or when one of the inverters fails, the rectifier loading is unbalanced. Under such an eventuality, which is a most frequently occurring case of failure in general, two of the rectifier units are fully loaded to 1.33MW, while the other unit is only half loaded to $0.665 \mathrm{MW}$. This becomes the analysis of interest in the discussions of this paper. For such an unbalanced case, a comparison is carried out with the balanced case and it is represented in the following figures and discussion.

Figure 9 shows the current waveform for the lightly loaded converter. The reduction in power is evident as the current is half that of Figure 4. The PWM voltage waveform determines the bridge current ripple. A small magnitude and phase change is required to generate the necessary $50 \mathrm{~Hz}$ current change in the input inductance. This requires small modulation changes which alter the current ripples so that ripple cancellation is less complete. Figure 10 shows the total primary side current. The increased $1800 \mathrm{~Hz}$ component resulting from reduced cancellation is not evident with the scale shown. These components are evident in the current spectrum shown in Figure 11. The current spectrum shows a distinct set of four switching lines around $1800 \mathrm{~Hz}$. Figure 12 shows voltage harmonics around $1800 \mathrm{~Hz}$ that were not previously present. Figure 13 shows the harmonic currents in $1000 \mathrm{~Hz}$ - $2000 \mathrm{~Hz}$ range and these have increased to $1.33 \mathrm{~A} \mathrm{rms}$.

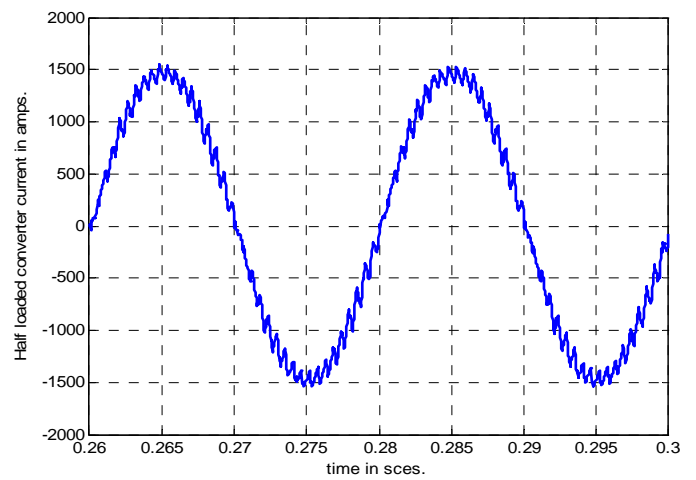

Figure 9. Half loaded Converter Current Waveform (Unbalanced case)

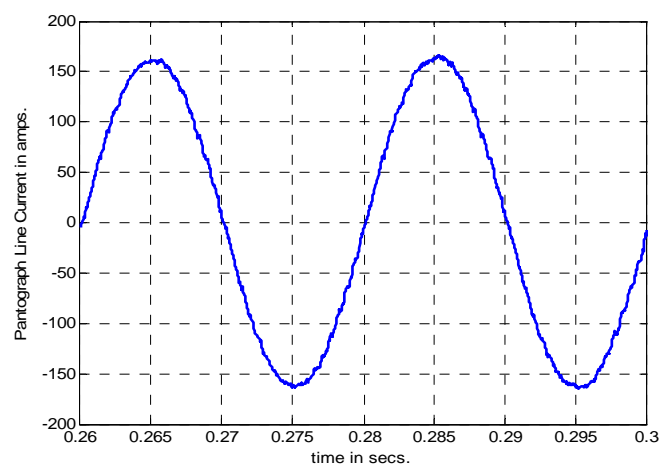

Figure 10. Pantograph Line Current Waveform With phase shifted Converters (Unbalanced case)

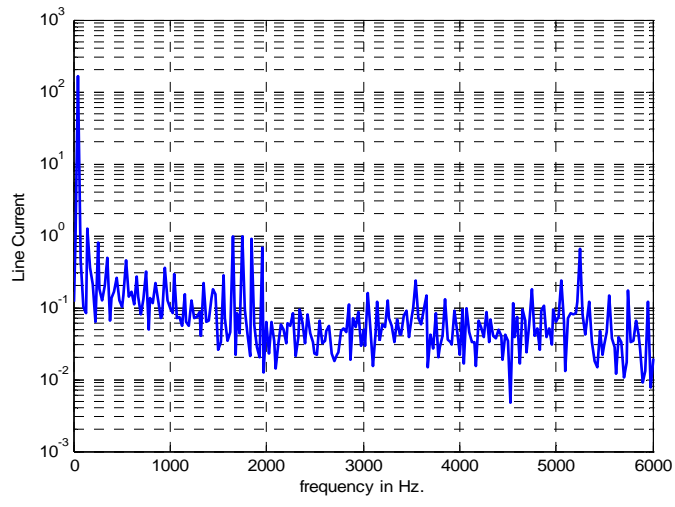

Figure 11. Pantograph Line Current Spectrum for the unbalanced case 


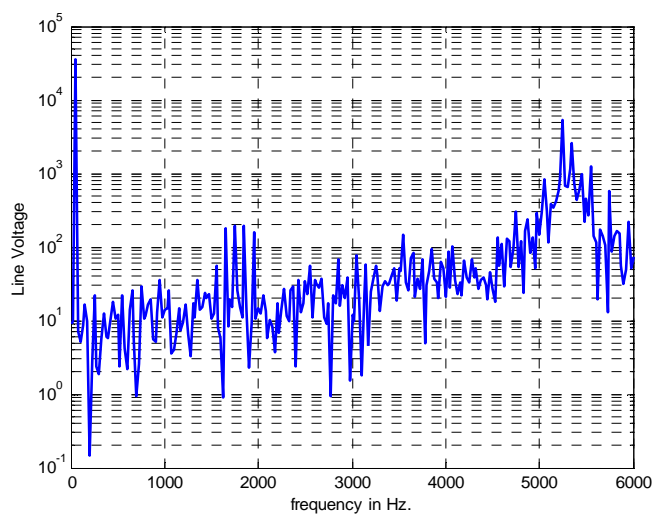

Figure 12. Pantograph Line Voltage Spectrum (Unbalanced case)

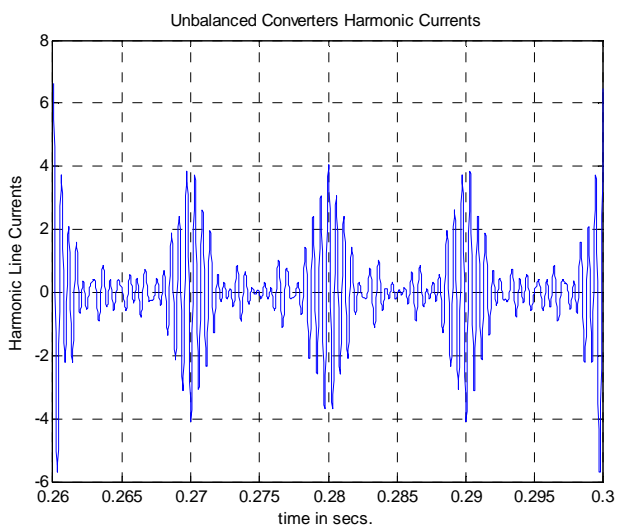

Figure 13. Harmonic Currents for the Unbalanced Converters for the frequency range of $1 \mathrm{kHz}-2 \mathrm{kHz}$

There can be different kinds of solutions for this type of frequently occurring problem. The most suitable solution to the problem depends upon the site conditions and requirements, keeping the right balance of both cost and performance of operation.

Passive filters can be used to absorb uncancelled harmonics. However, in a railway system, where vehicles move continuously on the track, it becomes quite difficult to predict or control the system characteristics. Consequently, a passive filter may absorb harmonics [8] generated by other vehicles. So, resistance damping might be quite necessary to limit the filter currents. This reduces the performance and results in losses. This paper will examine shunt active filter solutions as alternatives to passive solutions.

\section{SIMULATION RESULTS}

Active Filtering is a process of utilizing harmonic injection to eliminate or minimize harmonic distortion in the line current. Active filters use power electronic switching converters [3] to generate harmonic currents that cancel the harmonic currents from a non-linear load. The active filter is most effective when the load current waveform does not have abrupt changes. As a result, it is quite effective for voltage-source inverter type of loads. Clearly its rating is dictated by the main PWM converter RMS ripple current.
Active damping [9] on the other hand is used to improve the dynamics of the power system, thereby indirectly improving the THD of the line current. A current source may be controlled to provide resistive damping at all frequencies other than $50 \mathrm{~Hz}$. Suitable converter control is implemented by a notch filter. The distortion voltage is used to generate a demand signal for the controlled current shunt filter element.

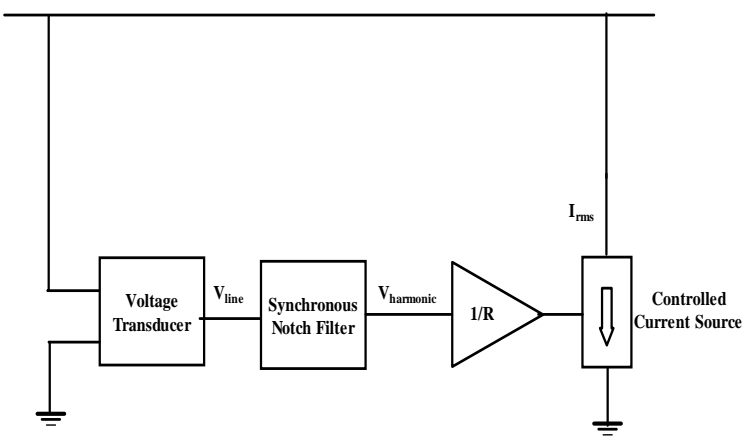

Figure 14. Active Filter/damper

Figure 14 shows an active damper solution for this problem of unbalanced converters. The harmonic voltage is identified using a synchronous reference frame notch filter [10] to remove the fundamental component of the supply current waveform. All the fundamental components are frequency shifted to DC. Second order low pass filters are employed for filtering purpose. The controlled current source simulates a resistor at harmonic frequencies.

Figure 15 shows the simulated results of the psophometric currents in the frequency range of $1 \mathrm{kHz}$ and $2 \mathrm{kHz}$, using an active filter/damper for the unbalanced converters. The total locomotive current in the $1 \mathrm{kHz}-2 \mathrm{kHz}$ frequency range is reduced to $172 \mathrm{~mA}$ rms.

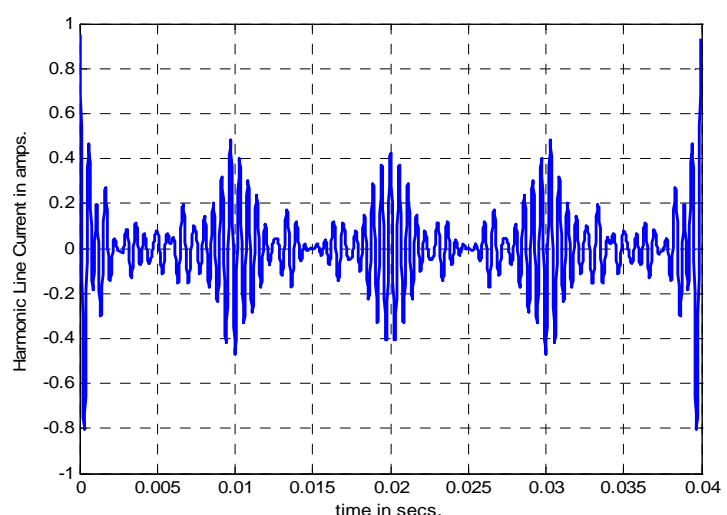

Figure 15. Harmonic Currents for the Unbalanced Converters with Active Filter for the frequency range of $1 \mathrm{kHz}-2 \mathrm{kHz}$

Figure 16 shows the line voltage is much cleaner with active damping, suppressing the $5400 \mathrm{~Hz}$ resonance as well. 


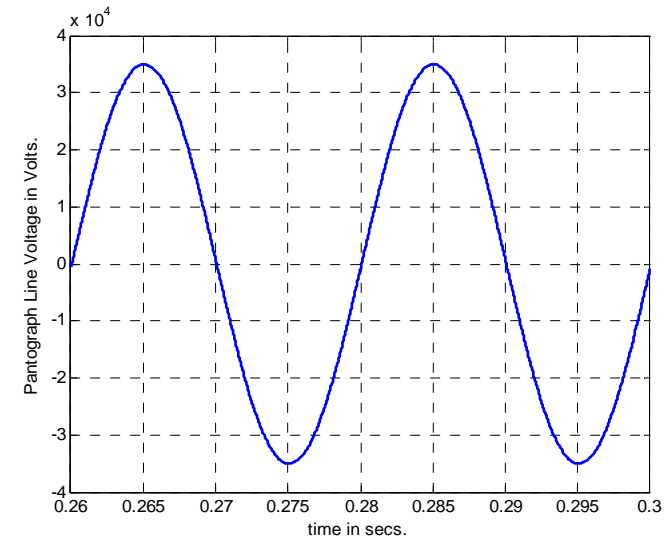

Figure 16. Pantograph Line Voltage with Active filter

\section{CONCLUSIONS}

The introduction of active dampers for this type of unbalanced operation of converters has provided an effective solution for reducing the harmonic currents in the line current spectrum of the traction converter system. It has been found that the harmonic current limits are within the permissible limits of operation for the railway signalling systems, thereby ensuring a secured and sustained operation of converters, even in the event of single point failures. This study has also proved that the safety critical limits of the harmonic currents imposed by the rail authorities need not be exceeded even under adverse operating conditions.

Future work will examine the reduction of the active element rating by using a hybrid filter solution. This uses a passive coupling network to allow filter currents to be injected without exposing the active element to mains frequency voltages and currents.

\section{ACKNOWLEDGEMENTS}

This work is supported by the Centre for Railway Engineering at Central Queensland University, Rockhampton, Australia.

\section{REFERENCES}

[1] J A Taufiq, "Step Response Prediction for Traction VSI Drive with emphasis on signaling compatibility”, IEEE, PESC 11-14 April 1988, Vol.2, pp.1271-1275

[2] D M Brooks, J A Taufiq, “Development of High Power GTO Inverter drives for low signalling interference currents”, International Conference on Main Line Railway Electrification, 25-28 Sept. 1989, pp.77- 81

[3] Mark McGranaghan, Electrotek Concepts, Inc. Knoxville TN, USA, “Active Filter Design and Specification for Control of Harmonics in Industrial and Commercial Facilities”

[4] A.Coccia, A. Del Pizzo, G. De Marco and M. Porzio, "Secondary Currents filtering by means of a properly sized winding in a multicoil traction transformer for high power applications to limit Psophometric Currents”, IEEE, PESC 2004, Vol.3, pp.1874-1880

[5] T Konefal, D A J Pearce, C A Marshman, L M McCormack, "Potential Electromagnetic Interference to Radio Services from Railways" Final Report for Radio Communications Agency (AY4110), By York EMC Services Limited, University of York, UK

[6] A. Coccia, A. Del Pizzo, R.Rizzo, “Auxiliary Winding of a Multibody Traction Transformer for filtering Psophometric Currents Produced by Interlaced Modulation of PWM Rectifiers", IEEE, PEDS 2003, Vol.1, pp.665-670

[7] Frank Flinders, Wardina Oghanna, “A New Minimum Input Distortion, Model Following Controller for Single Phase PWM Rectifiers", IEEE, Proceedings of the Industrial Symposium on Industrial electronics, (ISIE) 7- 11 July 1997, Vol.2, pp.606-611

[8] Bruno Busco, Alessandro Lo Schiavo, Pompeo Marino, Franesco Vasca, "Active Filtering of Low frequency Harmonics in DC/DC Converters for Traction Applications” IEEE, IECON 1999, Vol.3, pp.1421-1426

[9] Jason C. Wiseman, Bin Wu, “Active Damping Control of High-Power PWM Current-Source Rectifier for Line-Current THD Reduction”,IEEE Transactions on Industrial Electronics, Vol.52, No.3, June 2005, pp.758-764

[10] Vijay Kuppa, Peter Wolfs and Steven Senini, "Control of Traction Supply Power Quality using Locomotive PWM Converter Controls" AUPEC'03

[11] R E Morrison, Monash University, Victoria, Australia, "Power Quality Issues on AC Traction Systems”, Proc. Ninth Int. Conf. Harmonics and Quality of Power, 2000, pp. 709-714

[12] R.J.Hill, "Electric Railway Traction Part 4 Signalling and interlockings” Tutorial, Power Engineering Journal, 1995

[13] Bernhard Hemmer, Andrea Mariscotti and Dieter Wuergler, "Recommendations for the Calculation of the Total Disturbing Return Current From Electric Traction Vehicles”,IEEE Transactions on Power Delivery, Vol.19, No.3, July 2004, pp.1190-1197

[14] Joachim Holtz and Heinnz-Jurgen Klein, "The Propagation of Harmonic Currents Generated by Inverter-fed Locomotives in the Distributed overhead Supply System”IEEE Transactions On Power Electronics, Vol. 4, No.2, April 1989, pp.168-174

[15] S.Schmidt, D.Wuergler, Dr.Peter Terwiesch and Dr. Uwe Henning, "Electrical System Compatibility For Advanced rail Vehicles: A Survey”, International Conference on Harmonics and Quality of Power, 1998, Proceedings, Vol.2, 14-16 Oct.1998, pp.623-629

[16] J.A.Taufiq, C.J.Goodman and Prof.B.Mellitt, "Railway Signalling Compatibility of Inverter fed induction motor drives for rapid transit”, IEE Proceeedings, March 1986, Vol.133, Pt.B, No.2, pp.71-84 